\section{LAZER, JUVENTUDE E VIOLÊNCIA: UMA ANÁLISE DA LITERATURA VIGENTE}

\author{
LEISURE, YOUTH AND VIOLENCE: AN ANALYSIS OF CURRENT \\ LITERATURE C P
}

RECREACIÓN, JUVENTUD Y VIOLENCIA: UN ANÁLISIS DE LA

LITERATURA ACTUAL C

doi' https://doi.org/10.22456/1982-8918.105400

\section{iD Emerson Araújo de Campos* <emersoncampos.ec@gmail.com> \\ Ana Cláudia Porfírio Couto** <acpcouto@gmail.com> \\ Clara Faria e Barros** <clarafb.cf@gmail.com>}

Fábio Henrique França Rezende** <fabiohrezende94@gmail.com>

\author{
*Instituto Federal do Pará. Bragança, PA, Brasil. Universidade Federal de Minas \\ Gerais. Belo Horizonte, MG, Brasil. \\ **Universidade Federal de Minas Gerais. Belo Horizonte, MG, Brasil.
}

Resumo: Trata-se de um estudo de revisão integrativa sobre a temática lazer, juventude e violência, a fim de refletir sobre os seus resultados, ampliar possibilidades investigativas, apontar recorrências e lacunas, e indicar perspectivas de investigações. A fonte de coleta de dados foi o portal de periódicos da Capes, a base de dados SciELO e o Google Acadêmico. Há pelo menos duas discussões sobre a violência nas pesquisas analisadas, uma relacionada como barreira ao lazer, e a outra, que coloca o lazer como necessário para a recuperação de jovens que cometeram atos infracionais ou criminosos. Além disso, há estudos que apresentam os jovens como protagonista de suas vidas quando organizados em torno de práticas culturais e de lazer. Consideramos necessário investir em mais discussões que problematizem o lazer como atividade fundamental ao desenvolvimento humano, sem deixar de debater as contradições que ele pode apresentar aos jovens.

Palavras chave: Atividades de Lazer. Jovem Adulto. Violência. Conhecimento. Revisão.
Recebido em: 15 jul. 2020 Aprovado em: 30 jul. 2021 Publicado em: 28 ago. 2021

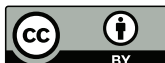

Este é um artigo publicado sob a licença Creative Commons Atribuição 4.0 Internacional (CC BY 4.0). elSSN: $1982-8918$ 


\section{INTRODUÇÃO}

Esta é uma pesquisa de revisão integrativa acerca da temática "lazer, juventude e violência", com o objetivo de refletir sobre os resultados de diferentes estudos e indicar pistas para novas investigações. Os objetivos são saber o que tem sido acumulado teoricamente, produzir novas compreensões e avançar na produção do conhecimento sobre o assunto.

Para isso, compreendemos que o lazer tem sido objeto de preocupações desde o final do século XIX no Brasil (MELO, 2001; GOMES; MELO, 2003; GOMES, 2011; SCHWARTZ, 2015). No campo científico, isso pode ser demonstrado pelo levantamento da produção do conhecimento, referente aos estudos do lazer, que indica a sua expansão durante o século XX e início do século XXI (PEIXOTO, 2007). Enquanto características gerais, essas produções científicas emergiram de diferentes áreas do conhecimento e apresentam uma diversidade de temas (MAGNANI, 2000). Além disso, tem-se um Programa de Pós-Graduação Interdisciplinar em nível de mestrado e doutorado, linhas de pesquisa em outros programas de pós-graduação, bem como disciplinas em diversos cursos de graduação universitária que estudam o fenômeno do lazer. Têm-se ainda dois eventos nacionais que são realizados periodicamente: o Encontro Nacional de Recreação e Lazer (ENAREL, realizado desde 1989) e o Congresso Brasileiro de Estudos do Lazer (CBEL), que a partir de 2014 substituiu o Seminário o Lazer em Debate (criado em 2000). Dentre os periódicos científicos especializados nacionais, que servem como outro importante indicador da dinâmica acadêmica da especialidade, destacam-se a revista Licere e a recém-criada Revista Brasileira de Estudos do Lazer (RBEL), ligada à Associação Nacional de Pesquisa e Pós-Graduação em Lazer (DIAS, et al., 2017).

Nesse contexto, compreende-se que os estudos do lazer no Brasil têm se preocupado com questões relacionadas à ocupação do tempo livre, os espaços públicos ou privados das cidades, os interesses culturais etc., a partir da realidade de diferentes sujeitos e/ou segmentos sociais. No conjunto dessas investigações, verifica-se que a juventude, ao lado da categoria infância, aparece como grupo social de grande ocorrência entre as publicações da revista Licere (MENEZES et al., 2018), um dos principais periódicos da área (ISAYAMA; MELO, 2014; MENEZES et al., 2017; SCHWARTZ, 2015; DIAS et al., 2017), o que pode sugerir que ela tem sido alvo de diferentes problematizações e tema de interesse entre os principais estudiosos do campo aqui denominado de estudos do lazer. Por outro lado, não temos um balanço de como a relação entre lazer, juventude e violência tem sido retratada nessas pesquisas.

Enquanto pistas, identificamos que estudos sobre jovens e violência quase sempre são realizados a partir dos "problemas" dessa categoria social, desconsiderando a compreensão dos modos de vida e das suas experiências. Essas pesquisas revelam alguns dos embates e/ou forças políticas que se conectam e se materializam na produção do jovem no contemporâneo, fixando-o em uma categoria conceitual ou objetivando-o a partir dos territórios de vulnerabilizações e violências que os envolvem (TAKEITI; VICENTIN, 2015; NOVAES, 2018). 
Para além dessas perspectivas, pesquisas sobre a ocupação do tempo livre pelos jovens são de significativa importância para se compreender os sentidos do próprio tempo da juventude nas sociedades. A dinâmica sociocultural da vida juvenil expressa, em grande medida, a realidade efetiva das coisas que organizam a vida dos jovens nas culturas vividas no lazer e no tempo livre. É, principalmente, nos tempos livres e nos momentos de lazer que os jovens constroem suas próprias normas e expressões culturais, seus ritos, suas simbologias e seus modos de ser. Por outro lado, há uma tendência da sociedade em enxergar nessas culturas traços de marginalidade, um tempo social potencialmente negativo e, em geral, pensado em oposição ao trabalho, este entendido como tempo de positividade, naquilo que se refere à formação humana. Além disso, a existência de tempo livre não implica necessariamente lazer. $O$ tempo livre do trabalho muitas vezes pode significar o espaço da penúria, da opressão e da falta de oportunidades (BRENNER; DAYRELL; CARRARO, 2008).

\section{MÉTODO}

A revisão integrativa busca desenvolver análise e síntese do estado do conhecimento de um determinado assunto, além de apontar lacunas do conhecimento que precisam ser preenchidas com a realização de novos. Desse modo, esse tipo de pesquisa permite a síntese de múltiplos estudos publicados e possibilita conclusões gerais a respeito de uma particular área de estudo (MENDES; CAMPOS; GALVÃO, 2008).

Para tanto, foram levantados estudos através da busca de publicações eletrônicas, dos últimos dez anos (2010-2020), que abordavam a temática lazer, juventude e violência, no portal de periódicos da Coordenação de Aperfeiçoamento de Pessoal de Nível Superior (Capes), na base de dados SciELO e no Google Acadêmico. Esse intervalo temporal compõe a primeira etapa de uma pesquisa que pretende se debruçar sobre outros períodos.

Os termos utilizados nas buscas foram: lazer, juventude, juventudes, jovem, jovens e violência. Esses termos foram inseridos nas diferentes bases de dados com quatro combinações diferentes. A primeira utilizou os termos lazer, juventude, violência; a segunda combinou lazer, juventudes, violência; a terceira lazer, jovem, violência; e a quarta lazer, jovens e violência. Os estudos foram reconhecidos pelos seus títulos, resumos e palavras-chave. Foram selecionados aqueles que mantinham relação direta com a temática pretendida, e excluídos os que não tratavam exclusivamente do assunto. Alguns estudos apresentavam discussões sobre a relação da juventude, lazer e violência, mas tinham como foco a discussão da violência na juventude, marginalizando o lazer, colocando-o como um acessório dos debates. Os estudos que foram selecionados pontuavam o lazer como elemento central das pesquisas, por isso foram selecionados.

Os estudos foram organizados e agrupados em temáticas e descritos através de seus objetivos e principais resultados. As temáticas emergiram da síntese das próprias pesquisas e foram pensadas em quatro categorias: manifestações culturais 
- estudos sobre formas de apropriação cultural pela juventude; ocupação do espaço público e uso do tempo livre - estudos sobre espaço público de lazer, uso do tempo livre e organização juvenil; futebol e torcida - pesquisas sobre o ambiente das torcidas como possibilidade de lazer; e programas sociais e políticas públicas - as potencialidades do lazer contra violências. Por fim, foram realizadas sínteses dos resultados com a intenção de verificar recorrências, apresentar lacunas e indicar perspectivas de estudos futuros.

\section{RESULTADOS E DISCUSSÕES}

Foram encontrados treze trabalhos, dos quais seis são artigos, seis são dissertações de mestrado e um é tese de doutorado. Cinco dissertações e a tese foram desenvolvidas no âmbito do Programa de Pós-Graduação Interdisciplinar em Estudos do Lazer (PPGIEL) (KANITZ JUNIOR, 2011; VIANA, 2013; SANTOS, 2013; CALDAS, 2017; SILVA, 2018), e uma dissertação no Programa de Pós-Graduação Conhecimento e Inclusão Social em Educação (PPGCIE) (SEPÚLVEDA, 2017), ambos da Universidade Federal de Minas Gerais (UFMG).

Os artigos foram publicados em diferentes periódicos, como na revista Motriz (PALHARES et al., 2012); Psicologia: Teoria e Pesquisa (NODARI et al., 2016); Licere (BRITO; SILVA; MARQUES, 2016); Saúde e Sociedade (LICO; WESTPHAL, 2014); Revista Katálysis (SEBENELLO; KLEBA; KEITEL, 2016); e Lúdica Pedagógica (GONÇALVES; FRANÇA; RECHIA, 2016). O Quadro 1 (na próxima página) demonstra os estudos selecionados.

Sobre os autores, a maioria são mestre ou doutores, com formação em Artes Visuais (SILVA, 2014; SILVA, 2018) ${ }^{1}$ Comunicação Social (NODARI, 2016), Ciências Políticas e Sociais (WESTPHAL, 2014) Educação Física (CALDAS, 2017; GONÇALVES, 2016; FRANÇA, 2016; RECHIA, 2016; SANTIAGO, 2012; SCHWARTZ, 2012; PALHARES, 2012; TREVISAN, 2012; TURIEL, 2012; KANITZ JUNIOR, 2011; SANTOS, 2013; SILVA, 2018), Geografia (SEPÚLVEDA, 2017; VIANA, 2013), Pedagogia (SILVA, 2014; SILVA, 2018), Psicologia (LICO, 2014; GUERRA, 2016; NASCIMENTO, 2016) e Terapia Ocupacional (BRITO, 2016). São oriundos de diferentes instituições de ensino superior públicas ou comunitárias, como: UFMG (BRITO, 2016; CALDAS, 2012; KANITZ JUNIOR, 2011; MARQUES, 2016; SEPÚLVEDA, 2017; VIANA, 2013; SANTOS, 2013; SILVA, 2014; SILVA, 2016; SILVA, 2018), Universidade Federal do Espírito Santo (UFES) (NODARI, 2016; ROSA, 2016; NASCIMENTO, 2016; GUERRA, 2016), Universidade Federal do Paraná (UFPR) (GONÇALVES, 2016; FRANÇA, 2016; RECHIA, 2016;), Universidade de São Paulo (USP) (LICO, 2014; WESTPHAL, 2014), Universidade Federal de Santa Catarina (UFSC), Universidade Estadual Paulista Júlio de Mesquita Filho (Unesp) (SANTIAGO, 2012; SCHWARTZ, 2012; PALHARES, 2012; TREVISAN, 2012; TURIEL, 2012). Têm formação continuada em diferentes cursos de pós-graduação², como: Estudos

1 Para indicar área de formação inicial e continuada e a instituição de vínculo do(a) autor(a) foi necessário buscar informações no currículo Lattes, quando estas não estavam disponíveis nos estudos analisados. Também consideramos, nesta etapa, cada autor(a) individualmente, uma vez que algumas produções são coletivas, por isso mantivemos as datas das publicações ao lado de cada sobrenome.

2 Consideramos a maior titulação. 
Quadro 1 - Pesquisas selecionadas

\begin{tabular}{|c|c|c|c|c|}
\hline Temática & Título & Tipo & Autor(es) (Ano) & Fonte \\
\hline \multirow{3}{*}{$\begin{array}{l}\text { Manifestações } \\
\text { culturais }\end{array}$} & $\begin{array}{l}\text { Capoeira angola na favela: juventudes, sentidos e redes } \\
\text { sociais }\end{array}$ & $\begin{array}{l}\text { Dissertação de } \\
\text { mestrado }\end{array}$ & Kanitz Junior (2011) & PPGIEL \\
\hline & Mulheres negras e baile funk: sexualidade, violência e lazer & $\begin{array}{l}\text { Dissertação de } \\
\text { mestrado }\end{array}$ & Viana (2013) & PPGIEL \\
\hline & $\begin{array}{l}\text { A palavra é sua! Os Jovens e os Saraus Marginais em Belo } \\
\text { Horizonte }\end{array}$ & $\begin{array}{l}\text { Dissertação de } \\
\text { mestrado }\end{array}$ & Sepúlveda (2017) & PPGCIE \\
\hline \multirow{2}{*}{$\begin{array}{l}\text { Ocupação do } \\
\text { espaço público e } \\
\text { uso do tempo livre }\end{array}$} & $\begin{array}{l}\text { A semana cultural no Colégio Estadual Gelvira Corrêa } \\
\text { Pacheco: Uma possibilidade de educação para o lazer }\end{array}$ & Artigo & $\begin{array}{l}\text { Gonçalves; França; } \\
\text { Rechia (2016) }\end{array}$ & Lúdica Pedagógica \\
\hline & Os usos do tempo livre entre jovens de classes populares & Artigo & $\begin{array}{l}\text { Nodari; Rosa; } \\
\text { Nascimento; Guerra } \\
\text { (2016) }\end{array}$ & $\begin{array}{l}\text { Psicologia: Teoria e } \\
\text { Pesquisa }\end{array}$ \\
\hline Futebol e torcida & $\begin{array}{l}\text { Lazer, agressividade e violência: considerações sobre o } \\
\text { comportamento das torcidas organizadas }\end{array}$ & Artigo & $\begin{array}{l}\text { Palhares; Schwartz; } \\
\text { Teruel; Santiago; } \\
\text { Trevisan (2012) }\end{array}$ & Revista Motriz \\
\hline \multirow{6}{*}{$\begin{array}{l}\text { Programas sociais } \\
\text { e políticas públicas }\end{array}$} & $\begin{array}{l}\text { A intervenção no lazer na política de segurança pública: a } \\
\text { construção de saberes de oficineiros no programa fica vivo! }\end{array}$ & $\begin{array}{l}\text { Dissertação de } \\
\text { mestrado }\end{array}$ & Santos (2013) & PPGIEL \\
\hline & Juventude, violência e ação coletiva & Artigo & Lico; Westphal (2014) & Saúde e Sociedade \\
\hline & $\begin{array}{l}\text { Lazer e juventude encarcerada: tensões entre trabalho, } \\
\text { disciplina e práticas culturais em uma unidade prisional da } \\
\text { APAC }\end{array}$ & Artigo & $\begin{array}{l}\text { Brito; Silva; Marques } \\
\qquad(2016)\end{array}$ & Licere \\
\hline & $\begin{array}{l}\text { Práticas de lazer e espaços públicos de convivência como } \\
\text { potência protetiva na relação entre juventude e risco }\end{array}$ & Artigo & $\begin{array}{c}\text { Sebenello; Kleba; Keitel } \\
(2017)\end{array}$ & Revista Katálysis \\
\hline & $\begin{array}{l}\text { Sentidos e significados da participação em projetos sociais de } \\
\text { lazer para a juventude do Aglomerado da Serra: trajetórias e } \\
\text { expectativas }\end{array}$ & $\begin{array}{l}\text { Dissertação de } \\
\text { mestrado }\end{array}$ & Caldas (2017) & PPGIEL \\
\hline & $\begin{array}{l}\text { Educação social e sistema prisional: o lazer entrelaçado às } \\
\text { práticas religiosas de jovens encarcerados em uma unidade } \\
\text { prisional da APAC }\end{array}$ & Tese de doutorado & Silva (2018) & PPGIEL \\
\hline
\end{tabular}

Fonte: elaboração própria realizada através de dados disponibilizados pelos sites das publicações.

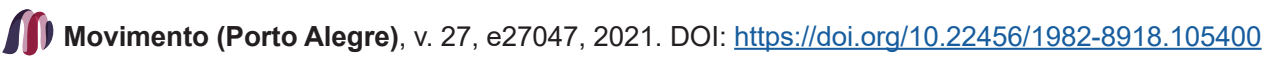


do Lazer (CALDAS, 2012; KANITZ JUNIOR, 2011; VIANA, 2013; SANTOS, 2013; SILVA, 2014; SILVA, 2016; SILVA, 2018), Educação (SEPÚLVEDA, 2017); Psicologia (NODARI, 2016; NASCIMENTO, 2016; MARQUES, 2016), Psicologia Social (GUERRA, 2016; ROSA, 2016), Psicologia Escolar e do Desenvolvimento Humano (SCHWARTZ, 2012), Ciências da Motricidade (PALHARES, 2012; SANTIAGO, 2012; TREVISAN, 2012), Saúde Pública (LICO, 2014; WESTPHAL, 2014), Educação Física (GONÇALVES, 2016; FRANÇA, 2016; RECHIA, 2016) e Comunicação e Semiótica (BRITO, 2016).

As pesquisas, em sua maioria, apresentam abordagem qualitativa (PALHARES et al., 2012; SANTOS, 2013; VIANA, 2013; SILVA, 2014; BRITO; SILVA; MARQUES, 2016; GONÇALVES; FRANÇA; RECHIA, 2016; SILVA, 2018), mas também quantitativa (NODARI et al., 2016), e são do tipo bibliográfica (PALHARES et al., 2012; SANTOS, 2013; SILVA, 2014; BRITO; SILVA; MARQUES, 2016; SILVA, 2018), documental (SANTOS, 2013; SILVA, 2018), etnográfica (SILVA, 2014; BRITO; SILVA; MARQUES, 2016; SILVA, 2018), de campo (SANTOS, 2013; CALDAS, 2017) ou fazem estudo de caso (LICO; WESTPHAL, 2014). Dentre as técnicas para coleta de dados, destacam-se a aplicação de questionários (LICO; WESTPHAL, 2014; GONÇALVES; FRANÇA; RECHIA, 2016; NODARI et al., 2016; SEPÚLVEDA, 2017), observação direta (GONÇALVES; FRANÇA; RECHIA, 2016) ou participante (KANITZ JUNIOR, 2011; VIANA, 2013; SILVA, 2014; BRITO; SILVA; MARQUES, 2016; SEPÚLVEDA, 2017; SILVA, 2018), entrevista semiestruturada (SANTOS, 2013; VIANA, 2013; LICO; WESTPHAL, 2014; SILVA, 2014; BRITO; SILVA; MARQUES, 2016; CALDAS, 2017; SEPÚLVEDA, 2017; SILVA, 2018), entrevista aberta temática (KANITZ JUNIOR, 2011), grupo focal (SILVA, 2018), grupo de discussão (VIANA, 2013), entrevista coletiva (CALDAS, 2017) ou roda de conversa (CALDAS, 2017), fotografia (SILVA, 2018). Quanto à análise de dados, houve ocorrência de análise do discurso, análise de conteúdo, com ou sem auxílio de software SPSS (NODARI et al., 2016) ou software Sphinx plus (LICO; WESTPHAL, 2014).

Os grupos juvenis investigados foram de moradores de bairros considerados periféricos (KANITZ JUNIOR, 2011; VIANA, 2013; SANTOS, 2013; LICO; WESTPHAL, 2014; SILVA, 2014; BRITO; SILVA; MARQUES, 2016; NODARI et al., 2016; CALDAS, 2017; SEPÚLVEDA, 2017; SILVA, 2018), em sua maioria negros e homens (KANITZ JUNIOR, 2011; SANTOS, 2013; SILVA, 2014; BRITO; SILVA; MARQUES, 2016; SILVA, 2018). Também foram alvo de estudo mulheres (VIANA, 2013), jovens de classe média e estudantes de escolas públicas (NODARI et al., 2016; GONÇALVES; FRANÇA; RECHIA, 2016). As pesquisas não trataram apenas de jovens moradores de capitais (KANITZ JUNIOR, 2011; VIANA, 2013; SANTOS, 2013; LICO; WESTPHAL, 2014 SILVA, 2014; BRITO; SILVA; MARQUES, 2016; SEPÚLVEDA, 2017; SILVA, 2018), mas também de cidades menores. Alguns grupos podem ser descritos com mais facilidade, dentre os quais destacam-se capoeiristas (KANITZ JUNIOR, 2011), membros de torcida organizada (PALHARES et al., 2012), frequentadores de baile funk (VIANA, 2013), alunos de projeto social (SANTOS, 2013; CALDAS, 2017), presidiários ou cumpridores de medidas protetivas ou socioeducativas (SILVA, 2014; BRITO; SILVA; MARQUES, 2016; SILVA, 2018). 


\subsection{MANIFESTAÇÕES CULTURAIS}

Os estudos incluídos nesta temática demonstram formas de apropriação cultural pela juventude e a superação de práticas de violência. Essa perspectiva se apresenta a partir dos anos 1990, de modo a oferecer um quadro importante das manifestações derivadas dos denominados grupos de estilos e culturas juvenis (SPÓSITO, 2010). Esses estilos vêm possibilitando práticas, relações e símbolos, por meio dos quais criam espaços próprios, significando uma referência na elaboração e vivência da condição juvenil, além de proporcionar a construção de uma autoestima e identidades positivas (DAYRELL, 2002).

Para tanto, a pesquisa Capoeira angola na favela: juventudes, sentidos e redes sociais (KANITZ JUNIOR, 2011) afirma que a capoeira angola estabelece redes sociais, entre os jovens e a comunidade, que possibilitam regras de conduta e comportamento social e negam a desvirtuação, ou qualquer tipo de envolvimento com práticas de contravenção. A capoeira angola, pelo menos no caso desse estudo, oportuniza espaço para reflexão, troca de experiências e busca de solução para problemas de diferentes ordens, além de estimular o exercício da solidariedade e da cidadania.

Em outro estudo, Mulheres negras e baile funk: sexualidade, violência e lazer (VIANA, 2013), faz-se uma análise do processo de construção social das feminilidades em um bairro popular favelizado e suas relações com a violência e o poder, nos momentos de lazer em bailes funk. Identificou-se que as trajetórias de vida das meninas/mulheres são marcadas por ações de enfrentamento em distintos territórios masculinos que questionam relações de gênero, decorrendo inicialmente em transgressões tanto em casa quanto na rua. O território funk representou um dos espaços favoráveis à crítica de uma realidade supostamente prescrita, na qual elas tornam-se sujeitos de suas ações produzindo um ethos feminino singular. Desse modo, o estudo inferiu que em determinados estilos musicais, como o funk, há possibilidades de se questionar a ordem social machista vigente em nossa sociedade, e que as jovens têm encontrado caminhos para subvertê-la.

Ainda no âmbito das discussões sobre juventude e manifestações culturais, em A palavra é sua! Os Jovens e os Saraus Marginais em Belo Horizonte (SEPÚLVEDA, 2017), analisaram-se os sujeitos e os possíveis sentidos produzidos pela participação em saraus. A pesquisa concluiu que os saraus marginais têm características comuns às formas de contestação juvenis contemporâneas, como a organização em coletivos, politização das ações culturais, encontro e ocupação do espaço público, produção cultural e artística também como forma de manifesto, trazendo à tona as questões urbanas, sociais, geracionais, raciais, de gênero, artísticas produzidas pelos sujeitos participantes.

A partir desses estudos, podemos inferir que o lazer não pode ser tomado como um fenômeno isolado, pois mantém relação com o contexto no qual está inserido. Ele pode encobrir contradições sociais, mas também agir como questionamento e resistência às injustiças sociais (GOMES, 2008). Por isso, acreditamos que as pesquisas relacionadas à temática manifestações culturais apresentam possibilidades para suplantar barreiras impostas aos jovens no âmbito do lazer e violência. Fazemnos refletir sobre como o acesso a determinados bens culturais, mesmo sem a 
intervenção do Estado, podem contribuir para a superação de problemáticas como a violência, o machismo, o racismo, as relações desiguais de gênero, o espaço público, dentre outros. Além disso, demonstram que a organização social em torno de manifestações culturais e práticas de lazer auxiliam para afirmação desses sujeitos jovens a partir de seus interesses, necessidades e a invenção de possibilidades.

\subsection{OCUPAÇÃO DO ESPAÇO PÚBLICO E USO DO TEMPO LIVRE}

Aqui, as pesquisas se debruçaram sobre aspectos relacionados ao espaço público para o lazer, ou as formas sob as quais a juventude se organiza, em um determinado tempo, para as atividades consideradas por eles como de lazer. Desse modo, os espaços públicos podem ser pensados como lugares que possibilitam relações sociais, além da atratividade que apresentam, visto que a inexistência de uma determinada forma de uso permite aos sujeitos utilizarem-no da melhor maneira possível (RECHIA, 2008). Por outro lado, existem alguns limites que podem criar barreiras no acesso aos espaços públicos de lazer, dentre as quais podemos destacar a segurança e a violência, como revelam os estudos aqui analisados.

A pesquisa A semana cultural no Colégio Estadual Gelvira Corrêa Pacheco: Uma possibilidade de educação para o lazer (GONÇALVES; FRANÇA; RECHIA, 2011) demonstra que, entre os motivos para a não ocupação do espaço público, o medo com a segurança foi destacado. Foi constatado que não se tem investimento em segurança, pois o local não é usado, e o local não é usado por não ter segurança. Além disso, ficou evidente a escassa participação dos discentes e da comunidade em geral no cuidado com aquilo que é público, além de um distanciamento da gestão pública no que se refere à manutenção e à segurança dos espaços e equipamentos de lazer do bairro.

Em Os usos do tempo livre entre jovens de classes populares (NODARI et al., 2016), foi identificado que a maioria das práticas de lazer de jovens de classes populares estavam circunscritas ao espaço da casa. A televisão, o acesso a internet e escutar música foram as principais atividades no âmbito do lazer em casa. Quando as práticas relacionadas ao lazer eram fora de casa, percebeu-se que o maior número de envolvidos eram os garotos. Atividades esportivas são mais comuns entre garotos e atividades de leitura entre as garotas. De modo geral, os resultados apontaram, principalmente, que os diferentes fatores envolvidos nas formas de apropriação do tempo livre entre esses jovens, não estavam relacionados estritamente à renda, mas também a aspectos como gênero, meio em que vivem, violência, estilos de vida e grupos de que participam.

Os dados reportados nos estudos dialogam com a pesquisa O Lazer do Brasileiro $^{3}$, quando foi identificado que as atividades no contexto do lazer mais

\footnotetext{
3 A pesquisa foi financiada pelo então Ministério do Esporte e objetivou conhecer o lazer do brasileiro buscando compreender três grandes questões: o que o brasileiro faz como lazer? O que gostaria de fazer, mas não faz como vivência de lazer? E por que não faz? Teve caráter qualitativo e quantitativo, realizada pela técnica do survey, por levantamento amostral, com a coleta executada por meio de entrevistas face a face, em pontos de fluxo, nas cidades previamente sorteadas. O instrumento de pesquisa foi um questionário estruturado, composto de perguntas abertas e fechadas. A amostra foi constituída por cotas representativas da população, considerando as variáveis de região e unidade da federação (cotas de sexo, idade, escolaridade e renda), conforme dados da população apurados no Censo Demográfico de 2010 (STOPPA; ISAYAMA, 2017).
} 
vivenciadas são assistir televisão e navegar na internet, bem como o local de preferência para usufruir de tempo de lazer é a casa (GRUBER; STOPPA, 2017). No entanto, o que se diferenciou é que nos estudos analisados aqui, a violência urbana é um dos maiores impeditivos para a vivência do lazer no espaço público, e a pesquisa O Lazer do Brasileiro indicou outras barreiras, como a falta de tempo, a saúde, a falta de recursos financeiros, questões relacionadas aos espaços e locais das atividades, o que talvez pudesse incluir a violência, mas não foi descrita dessa maneira.

A violência urbana contribui para exclusão socioespacial, o que interfere no dinamismo do espaço público e da vida citadina (SILVA, 2006). Por outro lado, interrogamos como a baixa participação da população, no uso dos equipamentos de lazer, pode interferir em pouco investimento em segurança pública e manutenção desses espaços. Talvez fosse mais adequado promover a adequação desses locais de lazer, com medidas conjuntas de acesso e uso, entre poder público e comunidade para que a população pudesse utilizar os equipamentos de lazer.

Ao pensar sobre espaço e tempo para o lazer da juventude, muitos elementos precisam ser analisados. Antes de mais nada, visualizar que o simples fato de haver espaço e tempo disponíveis não garante acesso ao lazer. Quando observamos o contexto das periferias, a violência, além de outros marcadores sociais, como renda e o gênero, representam implicações restritivas para o envolvimento em atividades no âmbito do lazer pelos jovens.

\subsection{FUTEBOL E TORCIDA}

Quando nos deparamos com o assunto das torcidas organizadas em nosso cotidiano, as primeiras impressões que podem emergir em nosso imaginário são de violência, e quase sempre acusamos um único segmento social como o responsável por ela, o torcedor. Por outro lado, no âmbito dos estudos do lazer, há certa negligência em pesquisas sobre as chamadas formas anormais de lazer, o que pode incluir os estudos em torno do futebol e das torcidas organizadas (ROJEK, 2011).

A produção científica nesse âmbito tem sugerido que é central conceber que os próprios torcedores organizados reconhecem seu envolvimento, e até mesmo protagonismo, no fenômeno da violência do futebol, sobretudo no aspecto da agressão física. Contudo, eles também denunciam formas de violência das quais são vítimas. Portanto, o torcedor não é somente executor de violência. As situações nas quais o torcedor comum ou organizado é vítima de violência acabam sendo minimizadas, relativizadas ou naturalizadas, afinal, a precariedade ou ausência de infraestrutura física e serviços no estádio, a ação extorsiva de flanelinhas, o alto custo do ingresso, o horário impróprio das partidas, o abuso e a coerção policial e a corrupção nas federações seriam "coisas do futebol” (PALHARES; SCHWARTZ, 2015).

Nesse contexto, o estudo Lazer, agressividade e violência: considerações sobre o comportamento das torcidas (PALHARES et al., 2012), que investigou, em estudos acadêmicos, o comportamento agressivo das torcidas organizadas e seus desdobramentos no tempo destinado ao lazer, indicou que, independentemente da gênese do comportamento agressivo, quando em presença de um grupo, ou 
dependendo do contexto socio-histórico, da composição das torcidas, da violência integrante da sociedade, da mídia, da má organização esportiva e da impunidade, estes fatores podem afetar mudança no comportamento individual, contribuindo para manifestações agressivas e violentas no âmbito futebolístico em campo e nas torcidas. Este tipo de manifestação pode favorecer a diminuição do público nos estádios, além de repercutir na delimitação das atividades vivenciadas no contexto do lazer. Estas condutas violentas podem, até mesmo, acarretar graves consequências nos âmbitos físico e/ou psíquico. Por fim, o estudo indica a premência de políticas públicas específicas envolvendo o lazer e os megaeventos.

O ambiente que envolve partidas de futebol e torcidas organizadas tem sido formatado pelo viés do controle, disciplina e adequação do torcedor a uma padronização de comportamento, justificada pela narrativa da segurança e não violência. Enquanto tecnologia de controle dos corpos não se estabeleceu apenas no contexto das torcidas organizadas, Foucault (2013) já falava dessa interferência no comportamento, no contexto de quartéis, conventos, instituições de ensino etc. especialmente a partir do século XVII e XVIII. Para ele, isso se configura como "[...] política das coerções que são um trabalho sobre o corpo, uma manipulação calculada de seus elementos, de seus gestos, de seus comportamentos. O corpo humano entra numa maquinaria de poder que o esquadrinha, o desarticula, o recompõe" ( $p$. 133), através da disciplina, que se diferencia de outras formas de dominação como asceticismo, a vassalagem, a domesticidade e a escravidão, e tem a vigilância como um de seus instrumentos. Desse modo, tenta-se instalar nos estádios de futebol espaços disciplinares (GAFFNEY; MASCARENHAS, 2006), porque se acredita que a aglomeração estimula a violência (LOPES; CORDEIRO, 2015).

A partir desse estudo, como pensar em estratégias de organização de eventos esportivos, especialmente para o futebol, que possam alinhar práticas não violentas contra as torcidas, contra os atletas, e entre os próprios torcedores? Como pensar o lazer sob o ponto de vista dos espetáculos esportivos e a erradicação de práticas violentas? Apesar de entendermos que esse fenômeno é complexo, a narrativa dos torcedores é pouco escutada, em contrapartida, o Estado tem destaque nos noticiários quando se mobiliza para coibir práticas de violência nas partidas de futebol, mas pouco questionado sobre a sua abordagem. Há muitos relatos de torcedores que sofrem com constante violência partindo da polícia. Quais seriam as consequências disso? Essas questões sugerem a necessidade de avançarmos com estudos nesse campo, para poder contribuir com políticas públicas no âmbito dos eventos esportivos em nosso país.

\subsection{PROGRAMAS SOCIAIS E POLÍTICAS PÚBLICAS}

Essa temática concentrou o maior número de pesquisas, o que indica sob qual aspecto os estudos no âmbito do lazer, juventude e violência têm maior aderência. De modo geral, e guardadas as generalizações, os estudos aqui localizados traduzem a ideia do lazer como importante elemento para o combate e superação da violência. São projetos de esporte, ações de entidades governamentais e não governamentais, dentre outros, que têm se destacado por implementar propostas de desenvolvimento 
físico-esportivo, em determinadas localidades carentes de serviços essenciais, que sofrem com taxas elevadas de violência. Com isso, a solução para o problema da violência estaria no desenvolvimento de esporte e lazer. Por outro lado, apesar de concordarmos com o potencial educativo e formativo do lazer, o formato dessas ações e a não articulação com outras esferas da vida, como saúde, habitação, e trabalho, parecem não ter tido resultados expressivos, conforme os estudos demonstram.

Apesquisa Aintervenção no lazer na política de segurança pública: a construção de saberes de oficineiros no programa fica vivo! (SANTOS, 2013) identificou saberes de profissionais de Educação Física que trabalham em programas para jovens em vulnerabilidade social, em áreas com altos índices de homicídios, e que tem como intenção de prevenir maiores estatísticas desses crimes. Ao mesmo tempo em que o lazer se articula com proteção social, processos de repressão, redução da mortalidade, gestão democrática, participativa e cidadã, também é visto como direito social que pode provocar o acesso e a circulação dos jovens nas cidades. O lazer também funciona como prevenção social do crime quando articulado às atividades educativas, culturais e esportivas, enquanto um saber contido nas intervenções dos oficineiros. Dessa forma, pode ser um instrumento e meio para construção de mentalidades ativas, através das manifestações culturais que engloba. É presente a ideia de que as atividades no tempo de lazer dos jovens servem para a ocupação dos espaços ociosos, onde o ócio é visto como espaço propício ao aparecimento de crimes e ações marginais.

As pesquisas Lazer e juventude encarcerada: tensões entre trabalho, disciplina e práticas culturais em uma unidade prisional da APAC (SILVA, 2014) e Lazer e juventude encarcerada: tensões entre trabalho, disciplina e práticas culturais em uma unidade prisional da APAC (BRITO; SILVA; MARQUES, 2016) buscaram investigar os significados e sentidos atribuídos às experiências de lazer de presos em um presídio configurado conforme o modelo da Associação de Proteção aos Condenados. Constatou-se que as práticas de lazer ocorreram em tempos e espaços reduzidos e que seus potenciais educativos e formativos não eram explorados. Então, nestes casos, a política pública prisional não se valeu do caráter educativo do lazer. $\mathrm{O}$ lazer era usufruído de maneira utilitarista, visando esgotar as energias dos detentos, acreditando que, dessa maneira, estaria prevenindo a violência entre os apenados.

A pesquisa Educação social e sistema prisional: o lazer entrelaçado às práticas religiosas de jovens encarcerados em uma unidade prisional da APAC (SILVA, 2018) investigou os significados e sentidos atribuídos às experiências religiosas entrelaçadas às práticas de lazer em um presídio configurado conforme o modelo da Associação de Proteção aos Condenados - APAC, na região metropolitana de Belo Horizonte/MG. Os resultados obtidos evidenciaram que as práticas religiosas não são capazes de proporcionar uma dimensão de transcendência, contudo, são usadas pelos jovens apenados como uma possibilidade momentânea de lazer. Ainda assim, ficou evidenciado o potencial educativo e formativo não explorado, tanto da atividade religiosa quanto do lazer.

Em Juventude, violência e ação coletiva (LICO; WESTPHAL, 2014), foram analisadas as ações coletivas e experiências participativas de promoção da saúde dos 
jovens, para o enfrentamento e resistência à violência, nos distritos administrativos do Grajaú e Jardim Ângela, visando contribuir para o desenvolvimento de políticas públicas direcionadas à juventude local. $\mathrm{Na}$ análise da rede de proteção aos jovens, constatou-se que as intervenções estavam voltadas principalmente para a redução do risco de violência, com foco na educação, cultura, desenvolvimento socioeducativo, esportes e lazer. As políticas públicas e ações coletivas destinadas à juventude eram fragmentadas e desarticuladas em ambos os distritos e os jovens não atuavam como protagonistas das ações. A rede de proteção aos jovens era difusa em ambos os Distritos, as escolas tinham papel preponderante e as entidades vocação para a prática assistencial. Verificou-se uma tendência de maior queda da taxa de mortalidade por agressões/homicídios no distrito do Jardim Ângela do que no de Grajaú. Apesar da redução registrada nos índices de violência estes ainda eram elevados nos dois distritos em relação ao restante do município.

No estudo intitulado Práticas de lazer e espaços públicos de convivência como potência protetiva na relação entre juventude e risco (SEBENELLO; KLEBA; KEITEL, 2016), buscou-se entender como jovens e seus pais, vinculados ao Serviço de Convivência de Fortalecimento de Vínculo, da Secretaria da Assistência Social de Chapecó/SC, reconheciam práticas e locais de lazer e riscos associados. Foi verificado que existiam discursos que patologizavam as práticas de lazer dos jovens, relacionandoas aos riscos e gerando preocupações, ao mesmo tempo em que buscavam criar estratégias de construção de autonomia, com monitoramento gradual do jovem para que este pudesse refletir sobre suas escolhas, principalmente diante de riscos, como o uso de álcool. Por outro lado, os jovens buscavam espaços de menor controle, como exercício de autonomia, o que demonstrou que as estratégias repressoras e de negação não funcionavam como estratégias protetivas. $O$ estudo revelou ainda que era necessário, enquanto rede de atendimento, colocar em debate discursos sobre a relação entre jovens, lazer e risco, pois havia uma acepção em culpabilizar as atitudes dos jovens. O risco visto como vulnerabilidade do jovem, no âmbito do lazer, era uma forma de reduzir as discussões, pois ignorava-se o quanto as opções eram restritas e as condutas em relação aos seus interesses, repressoras. Esse quadro fragilizou vivências de integração e participação social dos jovens, pois não compreendiam o lazer como direito, bem como sua potência na produção de experiências de desenvolvimento. Por isso, a pesquisa sugere transcender acepções de controle de risco e investir em espaços de integração social de jovens, dos jovens com suas famílias e na comunidade.

Por fim, na pesquisa Sentidos e significados da participação em projetos sociais de lazer para a juventude do Aglomerado da Serra: trajetórias e expectativas (CALDAS, 2017), foram identificados sentidos e significados da participação de jovens em projetos sociais de lazer. O estudo evidenciou que os jovens reconhecem o lazer como um direito fundamental, que percebem o preconceito para com a favela e seus moradores, a desigualdade de acesso aos direitos sociais e, especificamente, ao lazer, e a existência de projetos sociais voltados para as juventudes como uma forma de ocupar o tempo livre como algo "bom". Para além desta subjetivação, os jovens perceberam os projetos como possibilidade de aprendizagem, de diversão, de proteção, de acesso a bens culturais, de construção de novos laços de amizade, de realizar exercícios físicos e de inserção profissional. 
Os estudos aqui concentrados indicam o lazer como importante experiência de formação a jovens em programas de cuidado e atenção. Isso se dá porque o lazer foi relacionado a aspectos da proteção social, redução de violência e mortalidade, acesso a cidade, diversão, exercício físico, dentre outros, dando sentido a um tempo que seria ocioso, logo danoso. Por outro lado, medidas de controle, como aquelas relacionadas a determinadas escolhas consideradas não seguras, ou não saudáveis, como em práticas de lazer nas quais há consumo de bebidas alcoólicas, por exemplo, podem gerar conflitos e afastar os jovens desses programas e políticas. Os estudos mostraram a necessidade de superar práticas que procuram controlar interesses e necessidades, mas, ao invés disso, adotar estratégias que busquem dialogar e problematizar determinadas escolhas, para poder construir coletivamente estratégias e práticas que possam comportar a diversidade de interesses.

\section{CONSIDERAÇÕES FINAIS}

Esta pesquisa teve como objetivo realizar levantamento da produção científica sobre a temática lazer, juventude e violência, a fim de refletir sobre como tem tratado o tema, para ampliar possibilidades investigativas, fazer um balanço dos seus resultados, apontar recorrências e lacunas, e indicar perspectivas para futuras investigações.

Os grupos juvenis investigados são sujeitos das periferias das cidades, participam de grupos ou pontos de desenvolvimento de cultura, como a capoeira angola ou funk, são estudantes de escolas públicas, participantes de projetos sociais de esporte e lazer, membros de torcidas organizadas ou estão encarcerados. Em menor número, aparecem jovens de classe média nas pesquisas, o que revela que pesquisas sobre a relação lazer e violência têm grande aderência quando relacionadas a populações empobrecidas economicamente.

De modo geral, os estudos apresentam o lazer como atividade indispensável no combate à violência, tematizando jovens em privação de liberdade, por conta de medidas socioeducativas (SILVA, 2014; BRITO; SILVA; MARQUES, 2016; SILVA, 2018); a omissão do poder público e iniciativas das comunidades para a prevenção da violência (LICO; WESTPHAL, 2014; GONÇALVES; FRANÇA; RECHIA, 2016; NODARI et al., 2016; SEPULVEDA, 2017); políticas públicas como prevenção à violência (SEBENELLO; KLEBA; KEITEL, 2017; CALDAS, 2017); violências estruturais relacionadas a classe e raça (KANITZ JUNIOR, 2011) e a classe, raça e gênero (VIANA, 2013); além de violência física, verbal e psicológica relacionada a torcidas de futebol (PALHARES et al., 2012); bem como prevenção contra violência física através de programas sociais (SANTOS, 2013).

Há pelos menos duas discussões centrais sobre a violência nessas pesquisas. A primeira relaciona a limitação para a vivência do lazer com a violência presente na cidade. A segunda coloca o lazer como um tempo/espaço necessário para a recuperação de jovens que cometeram atos de violência. Ainda sobre esta segunda dimensão, os estudos demonstraram que o lazer pode ser um elemento de superação para atos de violência, mas alguns têm falhado, por causa de uma série de limites, 
dentre os quais destacamos a não compreensão dos interesses e necessidades dos jovens para a formatação das propostas de intervenção, o uso do lazer como instrumento de controle, o seu uso de modo utilitarista e desarticulado com outras políticas públicas, como saúde e educação.

Além disso, apesar de as pesquisas sobre jovens, quase sempre, desenvolverem-se a partir dos "problemas", e os estudos aqui levantados indicam essa compreensão, verificamos estudos que colocam o jovem como protagonista de intervenções. Foi identificado que em determinadas práticas de lazer, nas quais os jovens se compreenderam como sujeitos ativos, que compartilhavam seus problemas, decidiam e refletiam sobre como agir, organizavam ações coletivas, com espaço para liderar e construir conjuntamente com outros sujeitos, houve possibilidades para superar diferentes violências, como aquelas relacionadas ao machismo, ao racismo e às diferenças sociais de gênero.

Enquanto perspectivas, consideramos emergente a diversificação de estudos sobre a temática lazer, juventude e violência. Para isso, investir em discussões que continuem problematizando o lazer como atividade fundamental para o desenvolvimento humano, sem deixar de debater as contradições que ele pode apresentar, uma vez que, socialmente falando, ainda é visto ora como elemento que contribui para a violência, ora como remédio para ela, ou seja, quando estão ou não sob a tutela de uma organização ou grupo social.

Por fim, estudos que possam apresentar formas de organização social nas quais a juventude seja ativa dos processos de decisão são fundamentais. Algumas pesquisas demonstraram o quanto determinadas práticas ou projetos de lazer contribuíram para a constituição de identidades juvenis progressistas. Essas experiências nos apresentaram possibilidades de intervenção no âmbito de políticas públicas em esporte e lazer para e com a juventude. Afirmamos isso porque compreendemos que boa parte das políticas públicas destinadas à população, e neste caso especial para a juventude, não partem da realidade vivida, dos interesses e necessidades da sociedade.

\section{REFERÊNCIAS}

BRENNER, Anna Karina; DAYRELL, Juarez; CARRARO, Paulo. Juventude brasileira: culturas do lazer e do tempo livre. In: BRASIL. Ministério da Saúde. Fundação Oswaldo Cruz. Um olhar sobre o jovem no Brasil. Brasília, 2008. p. 29-44. (Série B. Textos Básicos de Saúde)

BRITO, Cristiane Miryan Drumond de; SILVA, Walesson Gomes da; MARQUES, Ernesto Ude Marques. Lazer e juventude encarcerada: tensões entre trabalho, disciplina e práticas culturais em uma unidade prisional da APAC. Licere, v. 19, n. 2, p. 37-71, jun. 2016.

Disponível em: https://periodicos.ufmg.br/index.php/licere/article/view/1235/873. Acesso em: 11 nov. 2019. 
CALDAS, Carolina Drumond Porto Carreira. Sentidos e significados da participação em projetos sociais de lazer para a juventude do Aglomerado da Serra: trajetórias e expectativas. 2017. 199f. Dissertação (Mestrado em Estudos do Lazer) - Escola de Educação Física, Fisioterapia e Terapia Ocupacional, Universidade Federal de Minas Gerais, Belo Horizonte, 2017.

DAYRELL, Juarez. O rap e o funk na socialização da juventude. Educação e Pesquisa, v. 28, n. 1, p. 117-136, jan./jun. 2002. Disponível em: http://www.scielo.br/pdf/ep/v28n1/11660. pdf. Acesso em: 20 mar. 2020.

DIAS, Cleber et al. Estudos do lazer no Brasil em princípios do século XXI: panorama e perspectivas. Movimento, v. 23, n. 2, p. 601-616, jun. 2017. DOI: https://doi. org/10.22456/1982-8918.66121

FOUCAULT, Michel. Vigiar e punir: nascimento da prisão. 41. ed. Petrópolis: Vozes, 2013.

GAFFNEY, Christopher; MASCARENHAS, Gilmar de Jesus. The Stadium as Disciplinary Space / O estádio como espaço disciplinar. Esporte e Sociedade, n. 1, 2006. Acesso em: https://ludopedio.com.br/biblioteca/the-soccer-stadium-as-a-disciplinary-spacel. Acesso em: 04 fev. 2019

GOMES, Christianne Luce. Estudos do lazer e geopolítica do conhecimento. Licere, v. 14, n. 3, set. 2011. Disponível em: https://periodicos.ufmg.br/index.php/licere/article/view/762. Acesso em: 20 nov. 2018.

GOMES, Christianne Luce. Lazer, trabalho e educação: relações históricas, questões contemporâneas. 2. ed. Belo Horizonte: Editora UFMG, 2008.

GOMES, Christianne Luce; MELO, Victor Andrade de. Lazer no Brasil: trajetória de estudos, possibilidades de pesquisa. Movimento, v. 9, n. 1, p. 23-44, jan./abr. 2003. DOI: https://doi. org/10.22456/1982-8918.2661

GONÇALVES, Felipe Sobczynski; FRANÇA, Rodrigo de; RECHIA, Simone. A semana cultural no colégio estadual Gelvira Corrêa Pacheco: uma possibilidade de educação para o lazer. Lúdica Pedagógica, n. 23, p. 63-70, 2016. Disponível em: https://revistas. pedagogica.edu.co/index.php/LP/article/view/4157/3568. Acesso em: 30 jan. 2020.

GRUBER, Gabriela Varjão; STOPPA, Edmur Antonio. O lazer do brasileiro: representações e concretizações nos espaços e equipamentos. In: STOPPA, Edmur Antonio; ISAYAMA, Hélder Ferreira. Lazer no Brasil: representações e concretizações das vivencias cotidianas. Campinas, SP: Autores Associados, 2017. p. 81-94

ISAYAMA, Helder Ferreira; MELO, Victor Andrade de. Licere: uma revista brasileira de lazer. Revista Brasileira de Ciências do Esporte, v. 36, n. 4, p. 773-779, 2014. Disponível em: https://www.scielo.br/j/rbce/a/J4FqKvwBwXrzQ3bf9QQk6RM/?lang=pt. Acesso em: 20 jan. 2020.

KANITZ JUNIOR, Roberto Malcher. Capoeira Angola na favela: juventudes, sentidos e redes sociais. 2011. 152f. Dissertação (Mestrado em Estudos do Lazer) - Escola de Educação Física, Fisioterapia e Terapia Ocupacional, Universidade Federal de Minas Gerais, Belo Horizonte, 2011.

LICO, Fátima Madalena de Campos; WESTPHAL, Márcia Faria. Juventude, violência e ação coletiva. Saúde Sociedade, v. 23, n. 3, p. 764-777, 2014. Disponível em: https:// www.scielo.br/j/sausoc/a/NYH6D37TbhtRtZPdmx5VDPF/abstract/?lang=pt. Acesso em: 10 nov. 2019. 
LOPES, Felipe Tavares Paes; CORDEIRO, Mariana Prioli. Futebol, visibilidade e poder: lógicas da violência nos espetáculos futebolísticos. Revista Comunicação Midiática, v. 10, n. 3, p. 119-134, 2015. Disponível em: https://www2.faac.unesp.br/comunicacaomidiatica/ index.php/CM/article/view/129. Acesso em: 04 fev. 2021.

MAGNANI, José Guilherme Cantor. Lazer: um campo multidisciplinar de pesquisa. In: BRUHNS, Heloísa Turini; GUTIERREZ, Gustavo Luís (orgs.). O corpo e o lúdico: Ciclo de Debates Lazer e Motricidade. Campinas: Autores Associados, 2000. p.19-33.

MELO, Victor Andrade de. Cidade Sportiva. Rio de Janeiro, Relume-Dumará, 2001.

MENDES, Karina D. S; CAMPOS, Renata C; GALVÃO, Cristina M. Revisão integrativa: método de pesquisa para a incorporação de evidências na saúde e na enfermagem. Texto \& contexto enfermagem, v. 17, n. 4, 2008. Disponível em: https://www.scielo.br/j/tce/al XzFkq6tjWs4wHNqNjKJLkXQ/. Acesso em: 13 jul. 2021.

MENEZES, Vilde Gomes de et al. A revista Licere e a pauta científica do lazer no Brasil de 1998 a 2017: uma revisão integrativa. Licere, v. 21, n. 2, p. 301-325, 2018. Disponível em: https://seer.ufmg.br/index.php/licere/article/view/11531. Acesso em: 20 nov. 2018.

NODARI, Manoela Pagotto Martins et al. Os usos do tempo livre entre jovens de classes populares. Psicologia: Teoria e Pesquisa, v. 32 n. 4, p. 1-9, 2016. Disponível em: https:// www.scielo.br/j/ptp/a/PT7DNj9m7XRxc4336wqdMmG/abstract/?lang=pt. Acesso em: 10 nov. 2019.

NOVAES, Allan. O jovem na literatura acadêmica: elementos para um estado da arte dos estudos da juventude. Fragmentos de cultura, v. 28, n. 2, p. 246-257, abr./jun. 2018. Disponível em: http://seer.pucgoias.edu.br/index.php/fragmentos/article/view/6001. Acesso em: 10 nov. 2019.

PALHARES, Marcelo Fadori Soares et al. Lazer, agressividade e violência: considerações sobre o comportamento das torcidas organizadas. Motriz, v. 18 n. 1, p.186-199, jan./mar. 2012. Disponível em: https://www.scielo.br/j/motriz/a/ MM8ZdR7r5Bhhd8kDM9zLDPM/?lang=pt. Acesso em: 10 nov. 2019.

PALHARES, Marcelo Fadori Soares; SCHWARTZ, Gisele Maria. Não é só a torcida organizada: o que os torcedores organizados têm a dizer sobre a violência no futebol?. São Paulo: Editora UNESP; São Paulo: Cultura Acadêmica, 2015. Disponível em: http://books. scielo.org/id/8zmft/pdf/palhares-9788579837425.pdf. Acesso em: 20 nov. 2018.

PEIXOTO, Elza. Levantamento do estado da arte nos estudos do lazer: (BRASIL) Séculos XX e XXI - alguns apontamentos. Educação Sociedade, v. 28, n. 99, p. 561-586, maio/ago. 2007. Disponível em: https://www.scielo.br/j/es/a/45FGTM75c8tR8GzrPbsg4XB/?lang=pt\&fo rmat=pdf. Acesso em: 08 set. 2019.

RECHIA, Simone. A política de lazer na cidade em pauta: a análise da gestão dos espaços em distintas realidades e segmentos populacionais. In: ENCONTRO NACIONAL DE RECREAÇÃO E LAZER, 20, 2008, São Paulo. Anais [...]. São Paulo: ENAREL, 2008. p. 1-8.

ROJEK, Chris. O lado obscuro do lazer: formas anormais. In: FORTINI, Janice Luce Martins; GOMES, Christianne Luce; ELIZALDE, Rodrigo. (orgs.). Desafios e perspectivas da educação para o lazer. Belo Horizonte: Editorial SEC/Otium, 2011. p. 137-148,

SANTOS, Samuel. A intervenção no lazer na política de segurança pública: a construção de saberes de oficineiros no programa Fica Vivo!. 2013. 144f. Dissertação (Mestrado em Estudos do Lazer) - Escola de Educação Física, Fisioterapia e Terapia Ocupacional, Universidade Federal de Minas Gerais, Belo Horizonte, 2013. 
SCHWARTZ, Gisele Maria. Pesquisas sobre lazer: visibilidade e perspectivas. In: GOMES, Christianne Luce; ISAYAMA, Hélder Ferreira (orgs.). O direito social ao lazer no Brasil. Campinas: Autores Associados, 2015.p.183-199.

SEBENELLO, Daiana Cristina; KLEBA, Maria Elisabeth; KEITEL, Liane. Práticas de lazer e espaços públicos de convivência como potência protetiva na relação entre juventude e risco. Revista Katálysis, v. 19, n. 1, p. 53 - 63, jun. 2016. Disponível em: https://periodicos.ufsc. br/index.php/katalysis/article/view/40282. Acesso em: 30 jan. 2020.

SEPÚLVEDA, Lucas Oliveira. A palavra é sua! Os jovens e os saraus marginais em Belo Horizonte. 2017. 135f. Dissertação (Mestrado em Educação) - Faculdade de Educação, Universidade Federal de Minas Gerais, Belo Horizonte, 2017.

SILVA, Raquel Coutinho Marques da. A urbanidade na cidade contemporânea entre fronteiras e trincheiras. In: SILVA, Raquel Coutinho Marques da. A cidade pelo avesso: desafios do urbanismo contemporâneo. Rio de Janeiro: Viana Mosley/ ProUrb, 2006. p. 2340.

SILVA, Walesson Gomes da. Educação social e sistema prisional: o lazer entrelaçado às práticas religiosas de jovens encarcerados em uma unidade prisional da APAC. 2018. $236 f$. Tese (Doutorado em Estudos do Lazer) - Escola de Educação Física, Fisioterapia e Terapia Ocupacional, Universidade Federal de Minas Gerais, Belo Horizonte, 2018.

SILVA, Walesson Gomes da. Lazer e juventude encarcerada: tensões entre trabalho, disciplina e práticas culturais em uma unidade prisional da APAC. 2014. 139f. Dissertação (Mestrado em Estudos do Lazer) - Escola de Educação Física, Fisioterapia e Terapia Ocupacional, Universidade Federal de Minas Gerais, Belo Horizonte, 2014.

SPÓSITO, Marília Pontes. Transversalidades no estudo sobre jovens no Brasil: Educação, ação coletiva e cultura. Educação e Pesquisa, v. 36, n. especial, p. 95-106, 2010. Disponível em: http://www.scielo.br/pdf/ep/v36nspe/v36nspea08.pdf. Acesso em: 20 mar. 2020.

STOPPA, Edmur Antonio; ISAYAMA, Hélder Ferreira. Introdução. In: STOPPA, Edmur Antonio; ISAYAMA, Hélder Ferreira. Lazer no Brasil: representações e concretizações das vivencias cotidianas. Campinas, SP: Autores Associados, 2017. p. 3-18.

TAKEITI, Beatriz Akemi; VICENTIN, Maria Cristina Gonçalves. A produção de conhecimento sobre juventude(s), vulnerabilidades e violência: uma análise da Pós-Graduação brasileira nas áreas de Psicologia e Saúde (1998-2008). Saúde Sociedade, v. 24, n. 3, p. 945-963, 2015. Disponível em: http://www.scielo.br/pdf/sausoc/v24n3/0104-1290sausoc-24-03-00945.pdf. Acesso em: 20 mar. 2020.

VIANA, lara Felix. Mulheres negras e baile funk: sexualidade, violência e lazer. 2013. 216f. Dissertação (Mestrado em Estudos do Lazer) - Escola de Educação Física, Fisioterapia e Terapia Ocupacional, Universidade Federal de Minas Gerais, Belo Horizonte, 2013. 
Abstract: This is an integrative review of leisure, youth and violence aimed at reflecting on its results, expand investigative possibilities, point out recurrences and gaps, and indicate prospects for investigations. The source of data collection was CAPES's journals portal, the SciELO database, and Google Scholar. There are at least two discussions about violence in the studies analyzed - one that sees it as a barrier to leisure, and the other that places leisure as necessary for the recovering young people who have committed criminal acts or violations. In addition, there are studies that present young people as protagonists of their lives when organized around cultural and leisure practices. We consider it necessary to invest in more discussions about leisure as a fundamental activity for human development, while debating the contradictions that it can pose to young people.

Keywords: Leisure Activities. Youth Adult. Violence. Knowledge. Review.

Resumen: Este es un estudio revisión integrativa sobre la temática de la recreación, la juventud y la violencia, con el fin de reflexionar sobre los resultados, ampliar posibilidades investigativas, señalar las recurrencias y lagunas e indicar las perspectivas de futuras investigaciones. Las fuentes de la recopilación de datos fueron el portal de revistas CAPES, la base de datos SciELO y la plataforma Google Scholar. Hay al menos dos discusiones sobre la violencia en las investigaciones analizadas, una que la relaciona como una barrera para el ocio y la otra que coloca el ocio como necesario para la recuperación de los jóvenes que han cometido actos delictivos o infractores. Además, hay estudios que presentan a los jóvenes como protagonistas de sus vidas cuando se organizan en torno a prácticas culturales y de recreación. Consideramos necesario invertir en más debates que problematicen el ocio como actividad fundamental para el desarrollo humano, sin dejar de debatir las contradicciones que puede presentar a los jóvenes.

Palabras clave: Actividades Recreativas. Adulto joven. Violencia. Conocimiento. Revisión. 


\section{LICENÇA DE USO}

Este é um artigo publicado em acesso aberto (Open Access) sob a licença Creative Commons Atribuição 4.0 Internacional (CC BY 4.0), que permite uso, distribuição e reprodução em qualquer meio, desde que o trabalho original seja corretamente citado. Mais informações em: https://creativecommons.org/licenses/by/4.0

\section{CONFLITO DE INTERESSES}

Os autores declararam que não existe nenhum conflito de interesses neste trabalho.

\section{CONTRIBUIÇÕES AUTORAIS}

Emerson Araújo de Campos: Planejamento da pesquisa, coleta de dados, análise dos dados, redação do artigo.

Ana Cláudia Porfírio Couto: Planejamento da pesquisa, coleta de dados, análise dos dados, redação do artigo.

Clara Faria e Barros: Planejamento da pesquisa, coleta de dados, análise dos dados, redação do artigo.

Fábio Henrique França Rezende: Planejamento da pesquisa, coleta de dados, análise dos dados, redação do artigo.

\section{FINANCIAMENTO}

O presente trabalho foi realizado sem o apoio de fontes financiadoras.

\section{COMO REFERENCIAR}

CAMPOS, Emerson Araújo de; COUTO, Ana Cláudia Porfírio; BARROS, Clara Faria e; REZENDE, Fábio Henrique França. Lazer, juventude e violência: uma análise da literatura vigente. Movimento (Porto Alegre), v.27, p.e27047, jan./dez. 2021. Disponível em: https://seer.ufrgs.br/Movimento/article/view/105400. Acesso em: [dia] [mês abreviado]. [ano]. DOI: https://doi.org/10.22456/1982-8918.105400

\section{RESPONSABILIDADE EDITORIAL}

Alex Branco Fraga*, Elisandro Schultz Wittizorecki*, Ivone Job*, Mauro Myskiw*, Raquel da Silveira*

*Universidade Federal do Rio Grande do Sul, Escola de Educação Física, Fisioterapia e Dança, Porto Alegre, RS, Brasil. 